\title{
Research Publications Output Among Academics in Pondicherry University: A Bibliometric Study (1987-2014)
}

\author{
Suresh C, Hema R, Sankarasubramaniam N \\ Central University \\ Pondicherry \\ India
}

\begin{abstract}
The 'Bibliometrics' and 'Scientometrics' are set of methods used for measuring the production and dissemination of the scientific knowledge's. The data used for the study were obtained from the SCOPUS Database. Totally 2885 record was found from the above database during the study period 1987-2014. The relative growth rates of output in terms of research productivity are analyzed among the periods. Out of 2885 publications 2 (0.06\%) of them published in 1987.9 (0.31\%) of them published in 1988. 6 (0.20\%) of them published in 1989. Simultaneously increased publications in recent years 196 (6.79\%) of them published in 2010. It is evident from the table that the highest 492 (17.05\%) publications published in the year of 2014. Out of 2885 publications Article comprises with 2251 (78.02\%) records, Conference paper comprises with 436 (15.11\%) records, Review comprises with 83(2.87\%) records, Book chapter comprises with 35 (1.21\%) records, Article in Press comprises with $21(0.72 \%)$ records etc. that the relative Growth rate and Doubling time for publications by Pondicherry University. It is clear that relative Growth rate of total research output is decreased gradually. The Growth rate is 1.17 in 1988 and which decreased up to 0.18 in 2014. The mean relative Growth rate for the periods of 1987 to 2014 the relative growth rate of 0.27. This study period resulted that the mean doubling time for total output 3.70. Author "Abbasi, S.A the highest number of publications for the study period with 149 (5.16\%) records.
\end{abstract}

Keywords: Bibliometrics, Scientometrics, Pondicherry University, Authorship Pattern, Relative Growth, Rate, Doubling Time

Received: $10.6025 / \mathrm{jism} / 2019 / 9 / 3 / 83-90$

DOI: 18 December 2018, Revised 8 March 2019, Accepted 9 May 2019

(C) 2019 DLINE. All Rights Reserved

\section{Introduction}

The term 'Bibliometrics' and 'Scientometrics' are synonymously used to measure researcher's science and technical development. 'Bibliometrics' is a type of research methods used in the field of Library and Information Science. This is a quantitative study of various aspects of literature on a topic and is used to identify the pattern of Publications, Authorship Pattern, Year Wise and Document wise distribution of coverage with the objectives of getting an insight into the dynamics of growth of knowledge in the related areas under consideration. The various 'Scientometric' indicators such ratio of Growth, Relative growth rate and Doubling time are used. The term scientometrics is often used with the meaning as the bibliometrics, originated in Russia. The application of quantitative methods to the history of science, Scientometrics is the science of measuring the science, which involves counting artifacts to the production \& use of information and arriving conclusions from the counts. Qualitative research

Journal of Information \& Systems Management Volume 9 Number 3 September 2019 
provides a pedestal to any university. India has prospered as far as the number of universities is concerned starting with 28 universities in $1950-51$, it has grown to about 737 today registering manifold increase. Growth in numbers is expected to cater to the increasing number of students. Research in a university speaks of the fertile minds and an environment of intellectual interaction in the university which will ultimately add credentials to the researchers as well as the universities concerned. In view of the above, it was intended to undertake a topic on "Research publications output among academics in Pondicherry University: A Bibliometric Study (1987-2014)". The study aims to ascertain the growth of literature, sources of publications, pattern of authorship, etc. by the academics of Pondicherry University during the period 1987-2014.

\section{Review of Related Literature}

Sevukan. R and Arivoli. J (2012) ${ }^{1}$. Their research paper was undertaken to study research trends among academics in Pondicherry University; a Bibliometric study. Their study covers a period of 12 years only spanning between 1998 and 2009, both years inclusive. Records for the analysis of this investigation were downloaded from the Databases of ISI Web of Science. The Relative Growth rate is 2.35 in 1999 which decreased up to 0.12 in the year of 2009. The mean Relative Growth rate for the periods during 1998-2003 and 2004-2009 are 0.71 and 0.15 respectively, whereas the study period has witnessed a mean relative growth rate of 0.43 . The mean Doubling time for the above two periods is 1.12 and 4.78 respectively. The whole study period resulted the mean Doubling time for total publications output is 2.95 Years. Surilinathi, M., Balasubramani, R., Kalisdha, A., (2013)². Their research paper was under taken continent wise analysis of green computing research: a Scientometric study. They collected data from Web of Science for the period of 1956-2011. Totally 3324 bibliographic records of contribution in field of Green Computing over the period of 56 years. Their paper attempts to analyze the growth and development of green Computing, as reflected in publication output covered by Web of Science online database during 1956-2011. Thanuskodi, S. (2011) ${ }^{3}$. Library herald journal: A Bibliometric study. International refereed research journal His research paper presents a Bibliometric analysis of the journal titled Library herald for the period during 2006-2010. His study mainly covers the number of Articles, Authorship Pattern, Subject wise distribution of articles, Average number of references per articles, forms of Documents cited, Year - wise distribution of cited journals.

\section{Objectives of the Study}

1. To analyze the Year wise distribution of publications by Pondicherry University.

2. To analyze the Document wise Publications.

3. To analyze Authorship Pattern.

4. To identify the ranking of Authors and based on publications.

5. To find out the Relative Growth Rate and Doubling Time for publications.

\section{Data Collection Source}

The data used for the study were obtained from the SCOPUS Database. The primary data for the research was collected from SCOPUS database. Totally 2885 record was found from the above database during the study period 1987-2014. The relative growth rates of output in terms of research productivity are analyzed among the periods.

\section{Limitations of the Study}

The study covers a period of 28 years spanning between 1987 and 2014, both years inclusive. Records for the analysis of this investigation were downloaded from the SCOPUS database. Though there are 15 schools, 37 departments in Pondicherry University, a few departments like Tamil, French, etc have been omitted as the publications of these disciplines are not covered in SCOPUS database.

Pondicherry University: A Profile

The Pondicherry University was established on October 16, 1985 by the Government of India through an Act of Parliament. It is

$84 \quad$ Journal of Information \& Systems Management $\quad$ Volume 9 Number 3 September 2019


a teaching-cum-affiliating central university. Being a Central University it is fully supported by the University Grants Commission. 15 Schools, 37 Departments and 10 Centres offering 175 PG \& Research programmes are within its fold and housed in the 800 acre sprawling Wi-Fi-enabled vibrant campus.

\begin{tabular}{|c|c|c|c|c|}
\hline S. No & Year & $\begin{array}{l}\text { No. of } \\
\text { Publications }\end{array}$ & Percentage & Cumulative \% \\
\hline 1 & 1987 & 2 & 0.06 & 0.06 \\
\hline 2 & 1988 & 9 & 0.31 & 0.37 \\
\hline 3 & 1989 & 6 & 0.20 & 0.57 \\
\hline 4 & 1990 & 23 & 0.79 & 1.36 \\
\hline 5 & 1991 & 14 & 0.48 & 1.84 \\
\hline 6 & 1992 & 12 & 0.41 & 2.25 \\
\hline 7 & 1993 & 12 & 0.41 & 2.66 \\
\hline 8 & 1994 & 20 & 0.69 & 3.35 \\
\hline 9 & 1995 & 12 & 0.41 & 3.76 \\
\hline 10 & 1996 & 45 & 1.55 & 5.31 \\
\hline 11 & 1997 & 39 & 1.35 & 6.66 \\
\hline 12 & 1998 & 36 & 1.24 & 7.9 \\
\hline 13 & 1999 & 48 & 1.66 & 9.56 \\
\hline 14 & 2000 & 44 & 1.52 & 11.08 \\
\hline 15 & 2001 & 73 & 2.53 & 13.61 \\
\hline 16 & 2002 & 82 & 2.84 & 16.45 \\
\hline 17 & 2003 & 76 & 2.63 & 19.08 \\
\hline 18 & 2004 & 75 & 2.59 & 21.67 \\
\hline 19 & 2005 & 76 & 2.63 & 24.3 \\
\hline 20 & 2006 & 88 & 3.05 & 27.35 \\
\hline 21 & 2007 & 85 & 2.94 & 30.29 \\
\hline 22 & 2008 & 111 & 3.84 & 34.13 \\
\hline 23 & 2009 & 132 & 4.57 & 38.7 \\
\hline 24 & 2010 & 196 & 6.79 & 45.49 \\
\hline 25 & 2011 & 293 & 10.15 & 55.64 \\
\hline 26 & 2012 & 360 & 12.47 & 68.11 \\
\hline 27 & 2013 & 424 & 14.69 & 82.8 \\
\hline 28 & 2014 & 492 & 17.05 & 100 \\
\hline \multicolumn{2}{|l|}{ Total } & 2885 & 100 & \\
\hline
\end{tabular}

Table 1. Year-Wise Distribution of Publications 


\section{Results and Analysis}

\section{Year-Wise Distribution of Publications}

Table -1 shows that distribution of year wise publications during the year $1987-2014$. Out of 2885 publications $2(0.06 \%)$ of them published in $1987.9(0.31 \%)$ of them published in $1988.6(0.20 \%)$ of them published in 1989. Simultaneously increased publications in recent years $196(6.79 \%)$ of them published in 2010. $293(10.15 \%)$ of them published in $2011.360(12.47 \%)$ of them published in 2012. 424 (14.69\%) of the published in 2013.492 (17.05\%) of them published in 2014 respectively. It is evident from the table that the highest $492(17.05 \%)$ publications published in the year of 2014.

\subsection{Document Wise Distribution of Publications}

Table 2 shows that document wise distribution of publications. Out of 2885 pucblications Article comprises with 2251 (78.02\%) records, Review comprises with 2251 (78.02\%) records, Conference paper comprises with 436 (15.11\%) records, Review comprises with 83 (2.87\%) records, Book chapter comprises with 35(1.21\%) records, Article in Press comprises with 21(0.72\%) records, Letter comprises with $21(0.72 \%)$ records, Erratum comprises with $10(0.34 \%)$ records, Note comprises with $6(0.20 \%)$ records, Short survey comprises with $5(0.17 \%)$ records, Book comprises with $1(0.3 \%)$ records, Unidentified comprises with $10(0.34 \%)$ records found of this study.

\begin{tabular}{|l|l|l|l|l|}
\hline S. No & Types of Documents & $\begin{array}{l}\text { No. of } \\
\text { Publications }\end{array}$ & Percentage & Cumulative \% \\
\hline 1 & Article & 2251 & 78.02 & 78.02 \\
\hline 2 & Conference Paper & 436 & 15.11 & 93.13 \\
\hline 3 & Review & 83 & 2.87 & 96.00 \\
\hline 4 & Book Chapter & 35 & 1.21 & 97.21 \\
\hline 5 & Article in Press & 21 & 0.72 & 97.93 \\
\hline 6 & Letter & 21 & 0.72 & 98.65 \\
\hline 7 & Erratum & 10 & 0.34 & 98.99 \\
\hline 8 & Editorial & 6 & 0.20 & 99.19 \\
\hline 9 & Note & 6 & 0.20 & 99.39 \\
\hline 10 & Short Survey & 5 & 0.17 & 99.56 \\
\hline 11 & Book & 1 & 0.03 & 99.59 \\
\hline 12 & Undefined & 10 & 0.34 & 100 \\
\hline Total & & 2885 & 100 & \\
\hline
\end{tabular}

Table 2. Doucument wise Distribution of publications

\section{Statistical Tool were used this Study}

\subsection{Relative Growth Rate}

The Relative Growth Rate and Doubling Time Model was developed by mahapatra and applied to examined the relative growth rate of research publications. The relative Growth rate is increased in the numbeer of publications. The relative Growth rate is increased in the number of publications or pages per unit of time and can be calculated from the following equations.

$$
\bar{R}(1-2)=\frac{W_{1}-W_{2}}{T_{2}-T_{1}}
$$

$86 \quad$ Journal of Information \& Systems Management Volume 9 Number 3 September 2019


Where, $\bar{R}(1-2)$ is mean Relative Growth Rate over the specified period

$W_{1}=\log W_{1}:$ (Natural log of initial number of Publications / Pages)

$W_{2}=\log W_{2}:$ (Natural log of initial number of Publications / Pages)

$T_{2}-T_{1}$ : The Unit difference between the initial time and Final time

The relative growth rate for both publications and pages can be calculated seperately. Therefore,

$\bar{R}(a)=$ Relative growth rate per unit of time (Year)

$\bar{R}(p)=$ Relative growth rate per unit of pages, per unit of time (Year)

\subsection{Doubling Time}

From the calculation. it is found that there is a direct equivalence existing between the relative Growth rates and Doubling time. if the numbers of Publications / Pages of a subject doubles during the given period, then the difference between the logarithm of the numbers at the end of the period must be the logarithms of the number two. if one uses a natural logarithm, this difference has a value of 0.693 . The corresponding doubling time for publications and pages can be calculated by using the following formula:

$$
\text { Doubling Time }(D t)=\frac{0.693}{\bar{R}}
$$

The corresponding doubling time for publications Data $\operatorname{Dt}(a)=\frac{0.693}{\overline{R(}(a)}$

$$
\text { Doubling Time for pages } D t(p)=\frac{0.693}{\overline{R(p)}}
$$

A study of data in table 3. indicates that the relative Growth rate and Doubling time for publications by Pondicherry University. It is clear that relative Growth rate of total research output is decreased gradually. The Growth rate is 1.17 in 1988 and which decreased up to 0.18 in 2014. The mean relative Growth rate for the periods of 1987 to 2014 the relative growth rate of 0.27 . This study period resulted that the mean doubling time for total output 3.70 .

\subsection{Authorship Pattern of Research Publications}

Table 4 projects the overall analysis of the pattern of authorship. The authors are classified according to their contribution that they have published. The total contribution made by academics of Pondicherry University comes to 2985 records over the period of study.

It could be noted that two authored papers rank first in order sharing 32.47 percent of the total research output. The three authored papers follow second in order taking 22.98 percent of the total research contributions. Four authored contributions take the third position in order sharing 16.67 percent of the total research output during the study period. Five authored papers rank next in order reporting 281 contributions that result 9.47 percent of total research output followed by 6 authored (5.06 percent), seven authored ( 2.14 percent), eight authored ( 0.97 percent), nine authored $(0.48$ percent), ten authored ( 0.38 percent) eleven and more authors ( 0.45 percent) publications.

\subsection{Ranking of Authors Based on the Publications}

Below the table 5. is shows that the ranking of authors by number of Publications. Author "Abbasi, S.A the highest number of publications for the study period with $149(5.16 \%)$ records, next nine consecutive authors namely Dhavachelvan, P $90(3.11 \%)$, Porsezian, K. 87 (3.01\%), Venkateswarlu, M 86 (2.98\%), Mathur, P.P.78 (2.70\%), Govindaraj, G. 67 (2.32 \%), Rao, P.S 61 (2.11\%), Abbasi, T. 60 (2.07 \%), Sambasiva Rao, P. 59 (2.04 \%), Ravikumar, R.V.S.S.N. 58 (2.01\%) respectively. 


\begin{tabular}{|c|c|c|c|c|c|c|c|c|}
\hline Year & $\begin{array}{l}\text { No. of } \\
\text { Publications }\end{array}$ & \begin{tabular}{|c|}
$\begin{array}{c}\text { Cumulative } \\
\text { of } \\
\text { Publications }\end{array}$ \\
\end{tabular} & W1 & W2 & $\begin{array}{l}\mathrm{R}(\mathrm{a}) \\
\mathrm{W} 2-\mathrm{W} 1\end{array}$ & $\begin{array}{l}\text { Mean } \\
\text { R(a) } \\
(1-2)\end{array}$ & $\begin{array}{l}\text { Doubling } \\
\text { time } \\
\text { Dt(a) }\end{array}$ & $\begin{array}{l}\text { Mean } \\
\text { Dt(a) } \\
(1-2\end{array}$ \\
\hline 1987 & $2(0.06)$ & 2 & - & 0.69 & & \multirow{28}{*}{-0.27} & - & \multirow{29}{*}{3.70} \\
\hline 1988 & $9(0.31)$ & 11 & 0.69 & 2.39 & 1.7 & & 0.40 & \\
\hline 1989 & $6(0.20)$ & 17 & 2.39 & 2.83 & 0.44 & & 1.57 & \\
\hline 1990 & $23(0.79)$ & 40 & 2.83 & 3.68 & 0.85 & & 0.81 & \\
\hline 1991 & $14(0.48)$ & 54 & 3.68 & 3.98 & 0.3 & & 2.31 & \\
\hline 1992 & $12(0.41)$ & 66 & 3.98 & 4.18 & 0.2 & & 3.46 & \\
\hline 1993 & $12(0.41)$ & 78 & 4.18 & 4.35 & 0.17 & & 4.07 & \\
\hline 1994 & $20(0.69)$ & 98 & 4.35 & 4.58 & 0.23 & & 3.01 & \\
\hline 1995 & $12(0.41)$ & 110 & 4.58 & 4.70 & 0.12 & & 5.77 & \\
\hline 1996 & $45(0.55)$ & 155 & 4.70 & 5.04 & 0.34 & & 2.03 & \\
\hline 1997 & $39(1.35)$ & 194 & 5.04 & 5.26 & 0.22 & & 3.15 & \\
\hline 1998 & $36(1.24)$ & 230 & 5.26 & 5.43 & 0.17 & & 4.07 & \\
\hline 1999 & $48(1.66)$ & 278 & 5.43 & 5.62 & 0.19 & & 3.64 & \\
\hline 2000 & $44(1.52)$ & 322 & 5.62 & 5.77 & 0.15 & & 4.62 & \\
\hline 2001 & $73(2.53)$ & 395 & 5.77 & 5.97 & 0.2 & & 3.46 & \\
\hline 2002 & $82(2.84)$ & 477 & 5.97 & 6.16 & 0.19 & & 3.64 & \\
\hline 2003 & $76(2.63)$ & 553 & 6.16 & 6.31 & 0.15 & & 4.62 & \\
\hline 2004 & $75(2.59)$ & 628 & 6.31 & 6.44 & 0.13 & & 5.33 & \\
\hline 2005 & $76(2.63)$ & 704 & 6.44 & 6.55 & 0.11 & & 6.3 & \\
\hline 2006 & $88(3.05)$ & 792 & 6.55 & 6.67 & 0.12 & & 5.77 & \\
\hline 2007 & $85(2.94)$ & 877 & 6.67 & 6.77 & 0.1 & & 6.93 & \\
\hline 2008 & $111(3.84)$ & 988 & 6.77 & 6.89 & 0.12 & & 5.77 & \\
\hline 2009 & $132(4.57)$ & 1120 & 6.89 & 7.02 & 0.13 & & 5.33 & \\
\hline 2010 & $196(6.79)$ & 1316 & 7.02 & 7.18 & 0.16 & & 4.33 & \\
\hline 2011 & $293(10.15)$ & 1609 & 7.18 & 7.38 & 0.2 & & 3.46 & \\
\hline 2012 & $360(12.47)$ & 1969 & 7.38 & 7.58 & 0.2 & & 3.46 & \\
\hline 2013 & $424(12.47)$ & 2393 & 7.58 & 7.78 & 0.2 & & 3.46 & \\
\hline 2014 & $492(17.05)$ & 2885 & 7.78 & 7.96 & 0.18 & & 3.85 & \\
\hline Total & 2885 & & & & & & & \\
\hline
\end{tabular}

Table 3. Relative Growth rate and doubling time for publications 


\section{Findings and Conclusion}

Bibliometric research has developed a body of theoretical knowledge and a group of techniques and applications based on the distribution of bibliographic data. The wider application of Bibliometric techniques is leading to the development of a new and

\begin{tabular}{|l|l|l|c|}
\hline Authorship Pattern & No. of Publications & Percentage & Cumulative Percentage \\
\hline 1 & 249 & 8.63 & 8.63 \\
\hline 2 & 937 & 32.47 & 41.1 \\
\hline 3 & 663 & 22.98 & 64.08 \\
\hline 4 & 481 & 16.67 & 80.75 \\
\hline 5 & 281 & 9.74 & 90.49 \\
\hline 6 & 146 & 5.06 & 95.55 \\
\hline 7 & 62 & 2.14 & 97.69 \\
\hline 8 & 28 & 0.97 & 98.66 \\
\hline 9 & 14 & 0.48 & 99.14 \\
\hline 10 & 11 & 0.38 & 99.52 \\
\hline 11 and above & 13 & 0.45 & 100 \\
\hline Total & 2885 & & \\
\hline
\end{tabular}

Table 4. Distribution of Authorship pattern of research publications

\begin{tabular}{|l|l|l|l|}
\hline S.No & Author & R.O/P & \% of 2885 \\
\hline 1 & Abbasi, S.A. & 149 & 5.16 \\
\hline 2 & Dhavachelvan & 90 & 3.11 \\
\hline 3 & Porsezian & 87 & 3.01 \\
\hline 4 & Venkateshwarlu, M., & 86 & 2.98 \\
\hline 5 & Mathur, P.P & 78 & 2.70 \\
\hline 6 & Govindaraj, G. & 67 & 2.32 \\
\hline 7 & Rao, P.S & 61 & 2.11 \\
\hline 8 & Abbasi, T. & 60 & 2.07 \\
\hline 9 & Sambasiva Rao, P. & 59 & 2.04 \\
\hline 10 & Ravikumar, R.V.S.S.N. & 58 & 2.01 \\
\hline
\end{tabular}

Table 5. Ranking of Authors based on Publications (Top 10 Ranked)

more precise technique. Hopefully, the on-going theoretical work will point the way to more innovative techniques. The highest publications $492(17.05 \%)$ were published in the year of 2014. The lowest publications $2(0.06 \%)$ were published in 1987 . Out of 2885 publications Article comprises with 2251 (78.02\%) records, Conference paper comprises with 436 (15.11\%) records, Review 
comprises with $83(2.87 \%)$ records, Book chapter comprises with 35 (1.21\%) records, Article in Press comprises with $21(0.72 \%)$ records found. The Growth rate is 1.17 in 1988 and which decreased up to 0.18 in 2014 . The mean relative Growth rate for the periods of 1987 to 2014 the relative growth rate of 0.27 . This study period resulted that the mean doubling time for total output 3.70 . Author "Abbasi, S.A the highest number of publications for the study period with $149(5.16 \%)$ records, next nine consecutive authors namely Dhavachelvan, P 90 (3.11\%), Porsezian, K. 87 (3.01\%), Venkateswarlu, M 86 (2.98 \%), Mathur, P.P.78 (2.70 \%), Govindaraj, G. 67 (2.32 \%), Rao, P.S 61 (2.11\%), Abbasi, T. 60 (2.07\%), Sambasiva Rao, P. 59 (2.04 \%), Ravikumar, R.V.S.S.N. 58 $(2.01 \%)$ respectively. This study has highlighted quantitatively the contributions made by the researchers during the years $1987-$ 2014 as available in SCOPUS database. During this 28 years contributions in terms of number of publications is significant. This present study also appears to be a milstone on the above said fact. This analysis of the present study for further reveals the applications of statistical techniques and tools and the generations of number of formula and equations that facilitate future researchers to test.

\section{References}

[1] Sevukan, R., Arivoli, J. (2012). Research trends among academics in Pondicherry University ; A Bibliometric Study. International Journal of Library and Information Science. 1 (1) 98-112.

[2] Surilinathi, M., Balasubramani, R., Kalisdha, A., (2013). Continent wise Analysis of Green Computing Research: a scientometric study, 2 (1) 39-44, Journal of Advances in Library and Information Science.

[3] Thanuskodi, S. (2011). Library Herald Journal: A bibliometric study. International Refereed Research Journal, 2 (4) 68 (accessed from www.researchersworld.com)

[4] Surulinathi, M. (2010). An evaluative study of Wi-Fi communication research publications: A Scientometric study, SALIS Journal of Information Management Technology, 1 (1) 32-40.

[5] Clarke A, et al. (2007). A bibliometric overview of public health research in Europe. European Journal of Public Health, 17(Sup.1): 43-49

[6] Chapula, C.A. (1998). Bibliometric analysis of AIDS literature in latin America and the Caribean. Scientometrics, 41 (2) $41-49$.

[7] Manivannan, G., Sanjeevi, K. (2012). A study on trend analysis of research output in Indian Journal of Medical Research [IJMR]. J. Lib. Advancements, 2 (2) 43-46. 